\title{
The Effect of Carbide Size, Morphology and Composition on the Rolling Contact Fatigue Properties of High Speed Steels Bearings
}

\author{
Dennis W. Hetzner \\ The Timken Company Canton, Ohio 44706 USA
}

Most bearings for piston-driven aircraft engines and early jet engines were made of through hardening 52100 steel or carburizing grades of alloy steels. However, as power requirements rose, operating temperatures increased, and alloys with more heat resistance became necessary. In the 1950's in Europe, T-1 and M-2 high-speed steel (HSS) were used for some jet engine applications. T1 contains tungsten, chromium and vanadium as the primary alloy elements. M-2 contains chromium, tungsten, vanadium and molybdenum. In the United States, M50 HSS, containing chromium, vanadium and molybdenum, was selected for bearing applications. The reason for selecting M50 was in this era the major sources of supply of tungsten were the former Soviet Union and other unstable countries. While these alloys displayed excellent hot hardness, the presence of large carbide particles and macroscopic banding of the carbides in the alloys could lead to early failures of bearings, Fig. 1. Electrolytic extraction reveals two morphologies of carbides in M50, long rods, and large plates, Fig. 2. M50-Nil, a carburizable version of M50 was developed in the early 1980's [1]. While this alloy removed the detrimental effects of the large carbides, it was found to be very difficult to carburize. In the 1990's, a unique laser glazing process was developed to improve the rolling contact fatigue properties of HSS bearings [2]. Compared to wrought M50, laser glazing increased the median test life of the bearings by $300 \%$, Fig. 3 . In addition, the laser glazing process refined the size of the carbides, and removed the macroscopic banding. While the laser glazing process was quite successful, it was more difficult to control than carburizing.

A careful review of early HSS literature indicated that in the early years of development of the HSS alloys, decarburization was a major problem. It was stated the presence of $4 \%$ chromium in these alloys helped to prevent oxidation, scaling and decarburization as well as increase the hardenability of the alloys [3]. The presence of $4 \% \mathrm{Cr}$ is exactly what makes M50-Nil difficult to carburize. Another paper graphically demonstrated the relationship between chromium, molybdenum, tungsten and vanadium on the quenched and tempered hardness of these alloys [4]. The combination of these two facts lead to the development of a new series of low chromium easily carburizable HSS alloys [5]. These alloys solved all the problems previously encountered with M50 and M50 Nil. The alloys can be carburized using conventional processing routinely performed for standard alloy steels. The carbides in the new steels are small and macroscopic banding is virtually eliminated, Fig 4. The median test life of bearings made from these alloys is $700 \%$ greater than bearings manufactured from M50 HSS, Fig. 5. These steels present two distinct advantages to both the manufacturers and users of bearings, ease of processing and greatly enhanced performance.

\section{References}

[1] E. N. Bamberger, et al. , 'U. S. Patent 4,659,241, 'Rolling Element Bearing Mebmer,' April 21, 1987.

[2] D. W. Hetzner, U. S. Patent, 5,861,067, 'Steel machine component having refined surface microstructure and process for forming the same,' January 19, 1999. 
[3] E. C. Bain and M. A. Grossmann, 'The Nature of the Function of Chromium in High Speed Steels,' Trans Asst, 6, 1924, p430.

[4] W. Crafts and J. L Lamont: Secondary Hardening of Tempered Martensitic Alloy Steel. AIME Met. Tech. September 1948. TP 2439.

[5] D. W. Hetzner, US Patent 6,702,981, "Low-carbon, low-chromium carburizing high speed steels,' March 9, 2004.

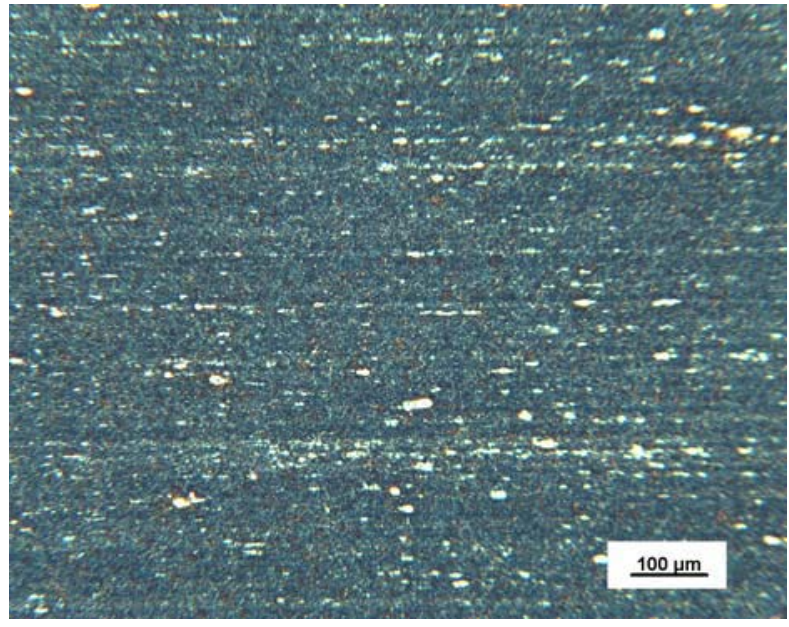

Fig. 1. Microstructural Banding - M50 HSS.

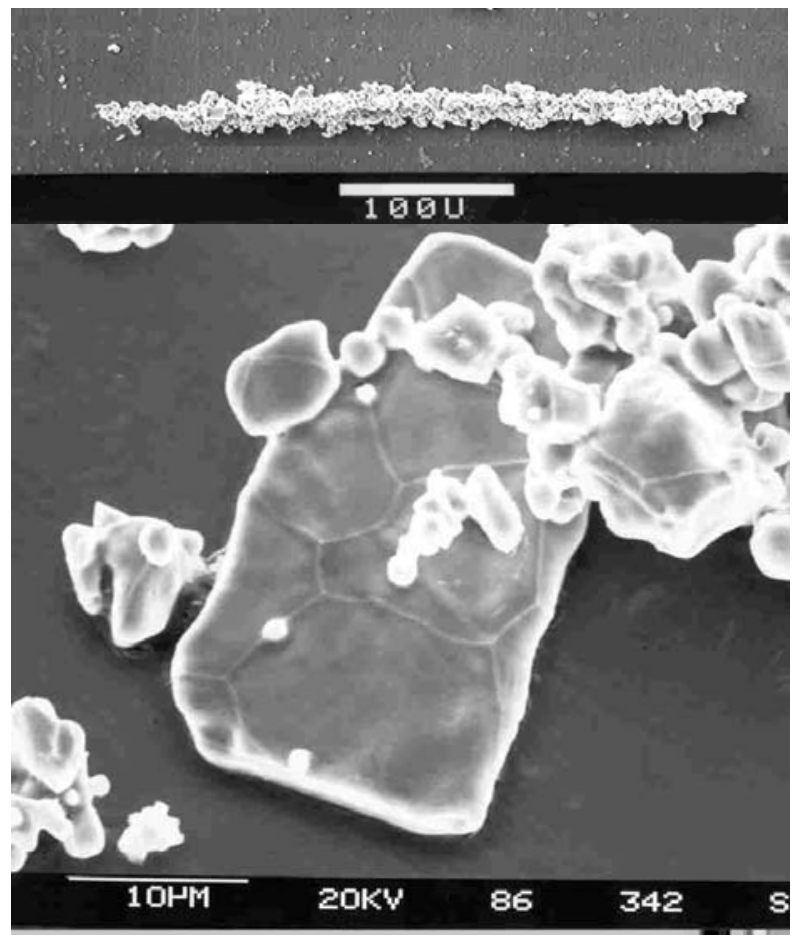

Fig. 2. Extracted rod and plate carbides, M50.

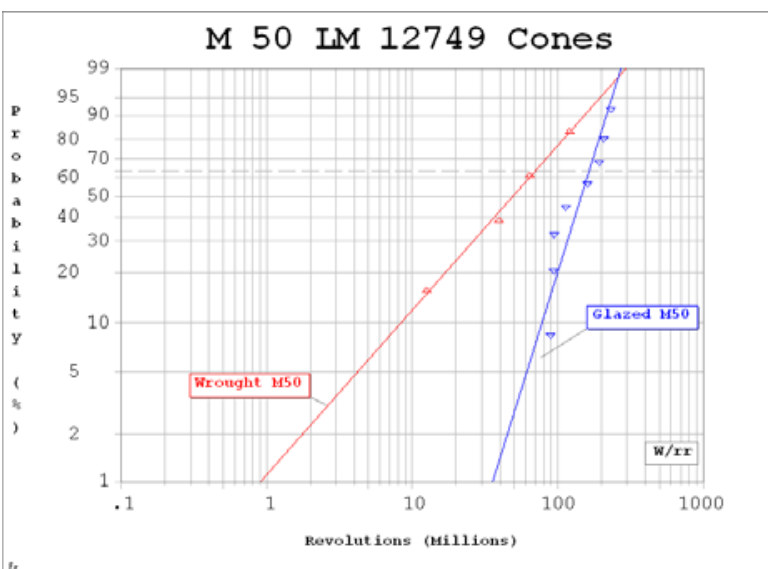

Fig. 3. Weibull analysis of wrought M50 and laser glazed M50.

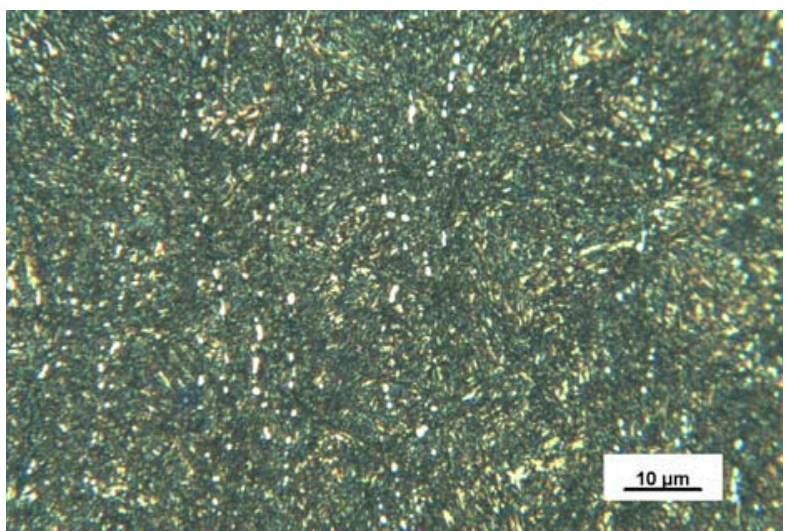

Fig. 4. Carburized CHS 50 - small carbides.

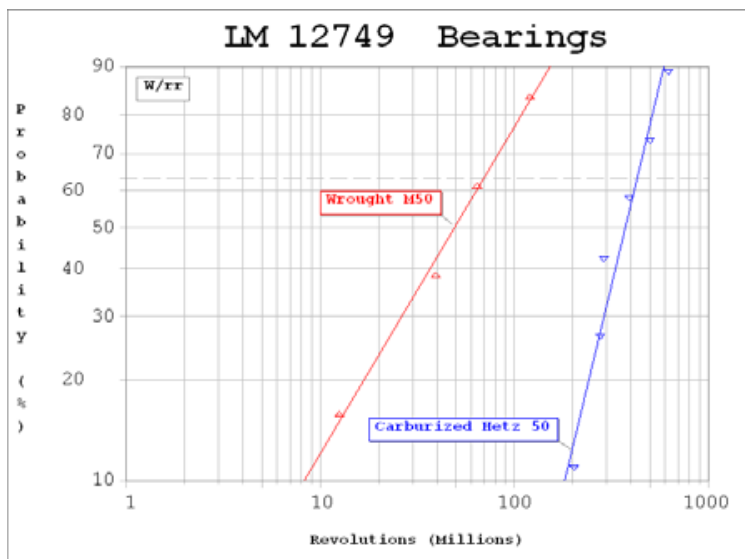

Fig. 5. Weibull analysis of wrought M50 and carburized CHS 50. 